Research Article

\title{
Generation and Evolution Conditions of Polygonal Wear of High-Speed Wheel
}

\author{
Yahong Dong $\mathbb{D}^{1,2,3}$ and Shuqian Cao $\mathbb{D}^{2,3}$ \\ ${ }^{1}$ School of Mechanical and Electrical Engineering, Lanzhou Jiaotong University, Lanzhou, Gansu, China \\ ${ }^{2}$ Department of Mechanics, School of Mechanical Engineering, Tianjin University, Tianjin, China \\ ${ }^{3}$ Tianjin Key Laboratory of Nonlinear Dynamics and Control, Tianjin, China \\ Correspondence should be addressed to Shuqian Cao; sqcao@tju.edu.cn
}

Received 17 September 2021; Accepted 20 October 2021; Published 20 November 2021

Academic Editor: Jiaqiang E

Copyright (c) 2021 Yahong Dong and Shuqian Cao. This is an open access article distributed under the Creative Commons Attribution License, which permits unrestricted use, distribution, and reproduction in any medium, provided the original work is properly cited.

\begin{abstract}
Wheel polygonal wear has long been a problem that confused the safety of railway operation which has important theoretical value and research significance. In this paper, the conditions of polygonal wear of high-speed wheel are analyzed based on the wear model and verified by the field measured data. Considering the wheel track interaction caused by rotation, a finite element model of wheelset rotor dynamics is established. The effects of rotor speed, mass eccentricity, wheelset, and track flexibility on the vibration characteristics of wheelset rotor system and wheel polygonal wear characteristics are analyzed by beam element and solid element, respectively. The results show that the wheel longitudinal vibration is the main reason of wheel polygonal wear, and the wheel polygonal wear follows the law of "constant frequency and divisible." Its "constant frequency" comes from the wheel track contact vibration, which stimulates the third-order vertical bending vibration of wheelset and the eighth-order coupled bending vibration of track, and the order is equal to the ratio of "constant frequency" to the wheelset rotation frequency.
\end{abstract}

\section{Introduction}

Polygonal wear of high-speed wheel has long troubled the safe operation of railway [1]. It not only arouses harmful vibration to the vehicle track system, causing damage or failure of vehicle and track components, but also increases vibration and noise during operation which can reduce the comfort of passengers and disturb the lives of residents along the line. At present, researchers have carried out relevant research on the wheel polygon problem by means of simulation or field test.

Meywerk [2] established a flexible wheelset model running on a flexible track, considering wheel track vibration in simulation. It was found that the first and second bending modes of the wheelset played an important role in the growth of polygon. Johansson and Andersson [3] found through a large number of field tests and numerical simulation that the fixed wavelength range of noncircular wheels is the vertical resonance zone of the vehicle track coupled system, which has high dynamic track stiffness. Wu et al. [4] established the multibody dynamics model of vehicle/track coupled and found that the high frequency vibration of wheel track contact may be the main reason for the generation of wheel polygon, and the main reason for the high frequency vibration in the frequency range of $500-800 \mathrm{~Hz}$ is the bending vibration modes of the track segment of two wheelsets. Ye et al. [5] pointed out that the wheel defects can cause or exacerbate wheel polygonization. Torstensson et al. [6] established the structural dynamics model of rotating flexible wheelsets considering the inertia effect of wheel rotation and found that more accurate results could be obtained by using the flexible rotating wheelset model to study high frequency contact forces. Brommundt [7] proposed that the evolution mechanism of wheel out of round is the result of interaction between initial wheel OOR (out of round) and the moment of inertia. Meinke [8] adopted the elastic beam element as the axle to establish a wheelset dynamics model with 40 degrees of freedom connecting the 
rigid wheel and brake disc and proposed that the dynamics of high-speed wheelset is determined by the gyroscopic moment and the inertial moment, which is different from the traditional wheelset. Jin et al. [9] made statistics on the polygonal wear test results of hundreds of wheels shortly after rotary cutting and found that eccentric wear occurred in $96 \%$ of wheels, and the proportion of other harmonic wear was $69 \%$ of 11 th order, $58 \%$ of 6 th order, and $35 \%$ of $3 \mathrm{rd}$ order, respectively.

Most of the existing studies are based on statistical analysis of field measured data or theoretical simulation from the perspective of wheel track or vehicle track coupled dynamics, and some conclusions related to wheelset bending or track bending modes have been found. However, the polygonal problem of wheel is prominent under high-speed operation increasingly, so the essence of the problem should be in the structure or characteristics of wheelset itself. Literature [6-8] all had put forward the necessity of considering flexible rotation to study wheel OOR, but few studies have been carried out based on rotor dynamics theory. The factors that affect the generation and development of polygon are very complicated, and there is no consistent understanding so far.

Therefore, this paper studies the generation and evolution mechanism of high order polygon wear of high-speed railway. Based on the wear model, the conditions of polygon wear of wheels were analyzed by theoretical analysis and field data verification. The finite element model of wheel-rotor dynamics considering mass eccentricity was established. Through the simulation and verification of beam element and solid element, the evolution law of "constant frequency and integer multiple" was found. The influence of wheel speed and wheel track flexibility on the generation and evolution of polygonal wear of wheels was studied. It provides an innovative perspective and theoretical basis for understanding the mechanism of generation and evolution of polygonal wear.

\section{Theoretical Analysis and Verification}

Firstly, based on the measured data of polygonal wear of wheel and the material wear model of wheel, the circular wear depth model of wheel was determined, from which the generation conditions of polygonal wear of wheel were found. Then, the wheelset rotor dynamic model was established to verify the vibration characteristics of polygonal wear of wheel, and combined with the established circumferential wear depth model, the evolution conditions and influencing factors of polygonal wear of wheel were studied. Figure 1 shows the research process of the generation and evolution conditions of wheel polygonal wear.

2.1. Circumferential Wear Model of the Wheel. Archard model and work model are usually used in polygonal wear prediction. The research shows that the trend of wheel polygonal generation and evolution corresponding to Archard model and wear work model are the same basically, but the wear coefficient in Archard model is relatively large, while the results of wear work model are closer to the field measured data, and the calculation efficiency is higher [10].
Therefore, the wear work model is adopted in the calculation of wheel wear in this paper.

The model based on wear work assumes that the wear mass $\Delta m$ is proportional to the wear energy that is dissipated in wheel track contact due to friction. The basic calculation principle is as follows.

Based on the wear work model, it is assumed that the wear mass of wheel contact spot is proportional to the friction work in the contact spot.

$$
\Delta m=K_{w} \cdot W_{w}
$$

where $\Delta m$ and $K_{w}$ are the wear mass of the wheel and the wear coefficient which is related to the wear energy per unit contact area in the contact spot and $W_{w}$ is the wear work in the contact spot.

The most realistic simulation of wheel wear is in the $3 \mathrm{D}$ and real time, which means that the $3 \mathrm{D}$ geometry of the wheel tread should change with each wheel rotation. However, this is either difficult in technology or timeconsuming. Moreover, polygonal wear of wheel mainly occurs in the circumferential direction. In order to simplify the simulation, some assumptions are listed as follows:

(1) Assuming that the lateral profile of the wheel is unchanged, only the change of the circumference profile of the wheel is concerned

(2) Assuming that the instantaneous wear of each contact spot on the tread is evenly distributed, calculate the average wear depth

(3) In short-term calculation, the change of wheel and track profile can be ignored

Literature [11] points out that wheelset longitudinal vibration has a significant impact on the profile and wear depth of wheel tread, and the wear is mainly concentrated near the rolling circle. If the radii of the wheel rolling circle $\theta$ are $R(\theta-2 \pi)$ and $R(\theta)$, respectively, the wear depth is $\Delta r=R(\theta-2 \pi)-R(\theta)$. In addition, the ware mass $\Delta m$ is the product of the wear depth $\Delta r$, the wear area $A_{w}$, and the material density $\rho$. The wear work $W_{w}$ is the product of the longitudinal creep force $F_{x}$ and the relative sliding distance between wheel and track $s_{w}$. Combined with (1), the calculation formula of wear depth $\Delta r$ can be obtained as

$$
\begin{aligned}
\Delta r & =R(\theta-2 \pi)-R(\theta) \\
& =\frac{\Delta m}{\rho A_{w}} \\
& =\frac{K_{w} \cdot W_{w}}{\rho \cdot A_{w}} \\
& =K_{w} \frac{F_{x} \cdot s_{w}}{\rho \cdot b_{w} \cdot s_{w}} \\
& =K_{w} \frac{F_{x}}{\rho \cdot b_{w}},
\end{aligned}
$$

where $b_{w}$ is the average width of the wear zone. 


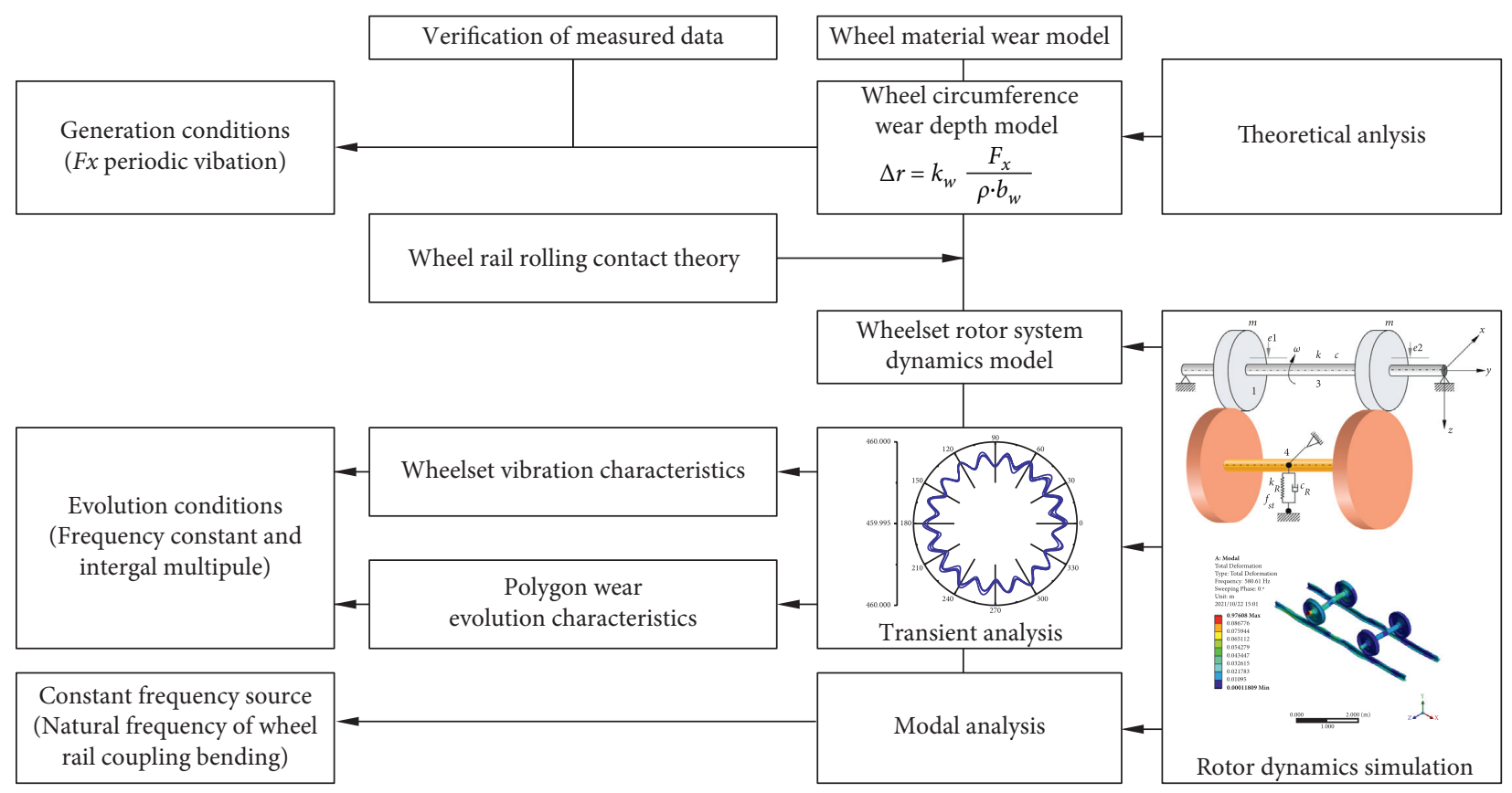

FIGURE 1: Research process of the generation and evolution conditions of wheel polygonal wear.

2.2. Conditions of Wear. It can be seen from formula (2) that wheel wear is related to longitudinal creep force $F_{x}$. When the longitudinal creep force changes periodically according to a certain frequency, it will lead to circumferential nonuniform wear with periodic change of wear depth $\Delta r$, resulting in polygon. When the longitudinal creep force is at its maximum, the wear occurs only once in a cycle of longitudinal wheel vibration.

If the longitudinal vibration frequency of the wheel is $f_{1}$ and the wheel rotation frequency is $f_{2}$, then the time interval between the two adjacent wear peaks is $1 / f_{1}$ and the wheel rotation cycle is $1 / f_{2}$, and the number of wear peaks $m$ within one rotation of the wheel is

$$
m=\frac{f_{1}}{f_{2}}
$$

The relation between wheel rotation frequency $f_{2}$ and train running speed is $f_{2}=v /(\pi D)$; then it can be known from equation (3) that the longitudinal wheel vibration frequency $f_{1}$ meets

$$
f_{1}=\frac{m v}{\pi D}
$$

where $v$ is the speed of vehicle and $D$ is the nominal diameter.

2.3. Test Verification. Field measurement of a certain type of EMU wheel shows that when the speed is $300 \mathrm{~km} / \mathrm{h}$, there are three high wear periods in the wheel diameter life cycle from $920 \mathrm{~mm}$ to $830 \mathrm{~mm}$, corresponding to the wheel diameters of $915 \mathrm{~mm}, 875 \mathrm{~mm}$, and $830 \mathrm{~mm}$, respectively. In these three wheel diameter stages, the measured wheel polygonal wear order is 20,19 , and 18 , respectively [9].
Based on formula (4), wheel angular velocity $\omega$, rotation frequency $f_{2}$, and longitudinal vibration frequency $f_{1}$ can be calculated from the above data. The result can be seen in Table 1.

It can be seen from Table 1 that the longitudinal vibration frequency corresponding to wheel polygonal wear is around $580 \mathrm{~Hz}$; that is, longitudinal vibration of wheel is the basic condition for generating wheel polygon wear, and its vibration frequency is fixed. This result verifies the research conclusion that wheel polygon wear has "constant frequency" mechanism [11].

\section{Polygonal Wear Model of the Wheel}

3.1. Wheelset Rotor Dynamics Model. The above analysis and related literature show that the longitudinal creep vibration of wheelset is the main reason for the generation and evolution of polygonal wear of wheel. It is necessary to analyze the state of longitudinal vibration of wheel and determine the range of parameters leading to longitudinal vibration of wheel.

The nonlinear problem of vehicle is very complicated due to its large structure and many degrees of freedom. Modeling is often conducted according to the research needs with specific focus, and the nonfocus items can be appropriately simplified in general. Therefore, wheelset axle box device is selected as the analysis object in this paper, as shown in Figure 2. The dynamics model of wheelset rotor system includes wheel 1 , wheel 2 , and axle 3 , as well as two large diameter axle disks 4 which are used to simulate track.

To analyze the basic characteristics of the rotor, it is assumed that

(1) The wheels are rigid disk 
TABLE 1: Calculation parameters of wheelset rotor system.

\begin{tabular}{lcccc}
\hline Diameter $D(\mathrm{~mm})$ & Angular velocity $\omega\left(\mathrm{rad}_{\mathrm{s}}{ }^{-1}\right)$ & Rotation frequency $f_{2}(\mathrm{~Hz})$ & Order $(N)$ & Longitudinal frequency $f_{1}(\mathrm{~Hz})$ \\
\hline 915 & 182.1 & 29.0 & 20 & 580.1 \\
875 & 190.5 & 30.3 & 19 & 576.3 \\
830 & 200.8 & 32.0 & 18 & 575.6 \\
\hline
\end{tabular}

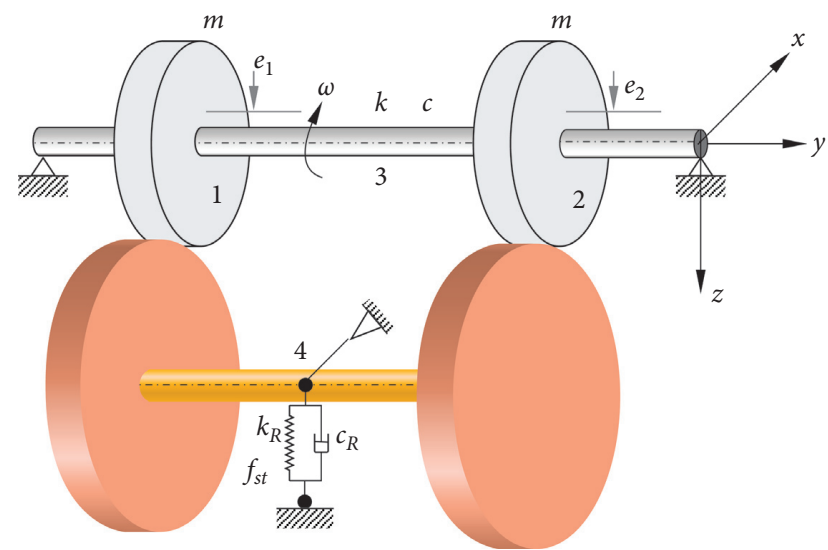

FIGURE 2: Dynamic model of wheelset rotor system.

(2) The axle is hollow with equal diameter, with a certain bending stiffness and infinite torsional stiffness, and both ends are supported by two identical bearings

(3) The bearing is simplified as hinged, and the mass is not considered

(4) The spring mass is equivalent to the track prepressure

As the left and right wheels are the same, one of them in Figure 2 is selected. Oxyz is taken as the fixed coordinate The intersection $O$ between the plane where the disk is located and the supporting points at both ends of the elastic axis is the origin of the fixed coordinate system, and $x$ axis is along the axis of the rotor, and the plane where the disk is located is the $O x z$ coordinate reference plane, as shown in Figure 3.

In the figure, $O_{1}$ and $C$ are the disk center of shape and mass, and the distance $O_{1} C$ is the eccentricity $e$. The mass of the disk is $m$, and we select $x(t)$ and $z(t)$ as the generalized coordinates of the disk center of shape $O_{1}$.

The wheelset use centralized mass element to simulate, and the shaft segment is simulated by Timoshenko beam element, and only two end nodes $(A$ and $B)$ in the beam element are used. Wheel track contact force is used to simulate wheel track contact. Figure 4 is a schematic diagram of Timoshenko beam element.

The nodes $A$ and $B$ in the Timoshenko beam element have 6 degrees of freedom, respectively, which are the displacement and rotation angles of the nodes in the $x, y$, and $z$ directions. The degree of freedom arrangement of beam elements is $u=\left[x_{A}, y_{A}, z_{A}, \theta_{x A}, \theta_{y A}, \theta_{z A}, x_{B}, y_{B}, z_{B} \theta_{x B} \theta_{y B}, \theta_{z B}\right]$ $\mathrm{T}$. Since the radial deformation of the joints in the model is much larger than its axial deformation, the axial and torsional deformation are ignored, and the degree of freedom of beam elements is simplified as $u=\left[x_{A}, z_{A}, \theta_{x A}, \theta_{z A}, x_{B}, z_{B}\right.$, $\left.\theta_{x B}, \theta_{z B}\right]^{\mathrm{T}}$. The dynamic equation of the whole rotor system can be expressed as

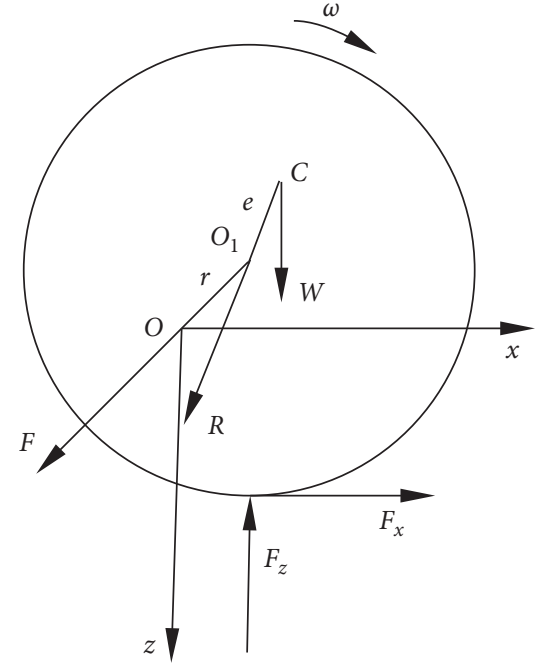

Figure 3: Disk instantaneous position and force.

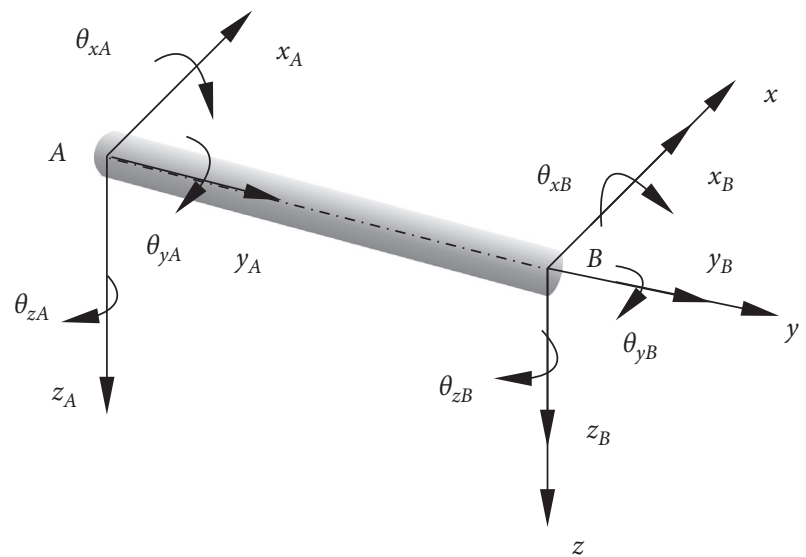

Figure 4: Timoshenko beam element.

$$
M \ddot{u}+(C+G) \dot{u}+K u=F_{e}+F_{r},
$$

where $M, C, G, K, F_{e}$, and $F_{r}$ are the mass matrix, damping matrix, gyro matrix, stiffness matrix, unbalanced force vector, and wheel track contact force vector, respectively, and $\ddot{u}, \dot{u}, u$ are acceleration, velocity, and displacement vectors of nodes in the model, respectively.

3.2. Wheel Track Rolling Contact Force. There are many theoretical models that have been studied and developed of wheel track rolling contact, including Kalker linear theory, Kalker simplified theory, Kalker three-dimensional accurate theory, and Shen's theory, among which Kalker's simplified theory is most widely used in railway field. Therefore, this 
paper carries out simulation analysis of wheel track rolling contact based on Kalker linear theory. The wheel track rolling contact force $F_{r}$ can be decomposed into longitudinal creep force $F_{x}$ and wheel track contact positive pressure $F_{z}$, which can be expressed as

$$
\left\{\begin{array}{l}
F_{x}=-\mathrm{GabC}_{11} \xi, \\
F_{z}=k_{R}\left(f_{s t}-z\right),
\end{array} \xi=\frac{v-\omega \cdot R}{v},\right.
$$

where $G, a$, and $b$ are shear elastic modulus of material, long and short half axes of contact spot, respectively, and $C_{11}, \xi$, $k_{R}$, and $f_{s t}$ are Kalker coefficient, longitudinal creep rate, support stiffness, and precompression amount of elastic support, and $v, R$, and $\omega$ are speed of elastic support, radius of disk, and rotational angular velocity of wheelset.

According to the eccentricity of the contact ellipse and the integral of the first and second complete ellipses, the contact spot length and the short semiaxis length can be determined as [12]

$$
\left\{\begin{array}{l}
a=m_{c}\left[\frac{3 \pi\left(\delta_{1}+\delta_{2}\right)}{2 \beta} F_{z}\right]^{1 / 3}, \\
b=n_{c}\left[\frac{3 \pi\left(\delta_{1}+\delta_{2}\right)}{2 \beta} F_{z}\right]^{1 / 3} .
\end{array}\right.
$$

We have

$$
\left\{\begin{array}{l}
m_{c}=\left[\frac{2 E_{p}}{\pi\left(1-e_{c}^{2}\right)}\right]^{1 / 3} \\
n_{c}=\left[\frac{2 E_{p} \sqrt{1-e_{c}^{2}}}{\pi}\right]^{1 / 3} \\
\delta_{i}=\frac{1-v^{2}}{\pi E_{i}} \\
\beta=\frac{1}{R_{11}}+\frac{1}{R_{12}}+\frac{1}{R_{21}}+\frac{1}{R_{22}}
\end{array}\right.
$$

where $E_{p}$ is the complete elliptic integral of the second kind; $E_{c}$ is eccentricity of contact ellipse; $v_{i}, E_{i}$ are Poisson's ratio and elastic modulus of contact $i(i=1,2)$, respectively. $R_{11}$, $R_{12}, R_{21}, R_{22}$ are the longitudinal and transverse principal radius of curvature of wheel and track along the contact coordinate system, respectively.

Zhao et al. found that the saturated creep force between wheel and track easily leads to the generation of polygon wear of wheel [13]. Therefore, the creep force saturation state is analyzed in this paper.

\section{Simulation of Wheel Polygonal Wear}

The shear modulus of wheel $G=7.9 \times 10^{10} \mathrm{~Pa}$, the Kalker coefficient $C_{11}=5.10$, the longitudinal half-axle length of contact spot $a=10 \mathrm{~mm}$, and the lateral half-axle length of contact spot $b=5 \mathrm{~mm}$. Main parameters of wheelset rotor system were selected by referring to $[14,15]$ measured in 1.3 , as shown in Table 2.
TABLE 2: Calculation parameters of wheelset rotor system.

\begin{tabular}{lcc}
\hline Parameter & Values & Unit \\
\hline The inner diameter of axle & 60 & $\mathrm{~mm}$ \\
The outer diameter of axle & 190 & $\mathrm{~mm}$ \\
Journal center distance & 1956 & $\mathrm{~mm}$ \\
Rolling circle distance & 1493 & $\mathrm{~mm}$ \\
Track stiffness $k_{R}$ & 20 & $\mathrm{MN} \cdot \mathrm{m}^{-1}$ \\
Wheel track creep factor $\mu$ & 0.25 & \\
Material density & 7860 & $\mathrm{~kg} / \mathrm{m}^{3}$ \\
Elastic modulus & $2.059 \times 10^{11}$ & $\mathrm{~Pa}$ \\
The wheel radius $D$ & 920 & $\mathrm{~mm}$ \\
Poisson's ratio & 0.3 & \\
\hline
\end{tabular}

4.1. Verification of Generation Conditions of Polygonal Wear. In order to verify the conclusion that wheelset longitudinal vibration based on the wear work model found in Section 1 is the basic condition for the generation of polygonal wear of wheels, the wheelset rotor dynamic finite element model in (5) is established. The wheelset rotation system is separated into 13 nodes, which are divided into 12 beam elements and 2 particle elements with 91 degrees of freedom in total. Bearing constraints are applied to nodes 1 and 13 corresponding to the left and right bearings, respectively. We also added the node function load corresponding to formula (6) of wheel track contact force on key points 2 and 4 corresponding to left and right wheels. We set the wheel mass and its eccentricity on key points 2 and 4 corresponding to the left and right wheels and added rotation frequency $f_{2}$ on the beam rotor.

In order to observe the influence of rotor speed and eccentricity on the vibration characteristics, transient analysis was conducted when $f_{2}=25.2 \sim 58 \mathrm{~Hz}$ and eccentricity $e=0.01 \mathrm{~mm}, 0.10 \mathrm{~mm}, 0.50 \mathrm{~mm}$, and $1.00 \mathrm{~mm}$. The three-dimensional spectra of the vertical displacement at the left wheel of the wheelset rotor system (Figure 5) and the spectra of the rotation frequency of $30 \mathrm{~Hz}$ (equivalent to $300 \mathrm{~km} / \mathrm{h}$ ) were obtained (Figure 6).

Figure 5 shows that wheelset vibration displacement is mainly composed of rotation frequency and high frequency under different eccentricity and rotor speed. With the increase of rotor speed, the degree of dynamic unbalance is aggravated due to the influence of flexibility and eccentricity of wheelsets, so the amplitude of both frequencies increases. The value of rotation frequency increases with the increase of rotor speed and eccentricity, but the high frequency value is always the same (approximately equal to $580 \mathrm{~Hz}$ ). The results of this study confirm that the "constant frequency" characteristics of polygonal wheel wear found in theoretical analysis and field tests.

When the rotation frequency is $30 \mathrm{~Hz}$, the spectrum of different eccentricity is shown in Figure 6. With the decrease of eccentricity, the amplitude of the rotation frequency gradually decreases until it disappears. The reason is that the degree of wheelset dynamic unbalance is improved. However, the constant frequency is $579.56 \mathrm{~Hz}$, and the corresponding amplitude changes little with the change of eccentricity, indicating that this frequency component is the "constant frequency" mentioned in the previous test and theoretical analysis. 


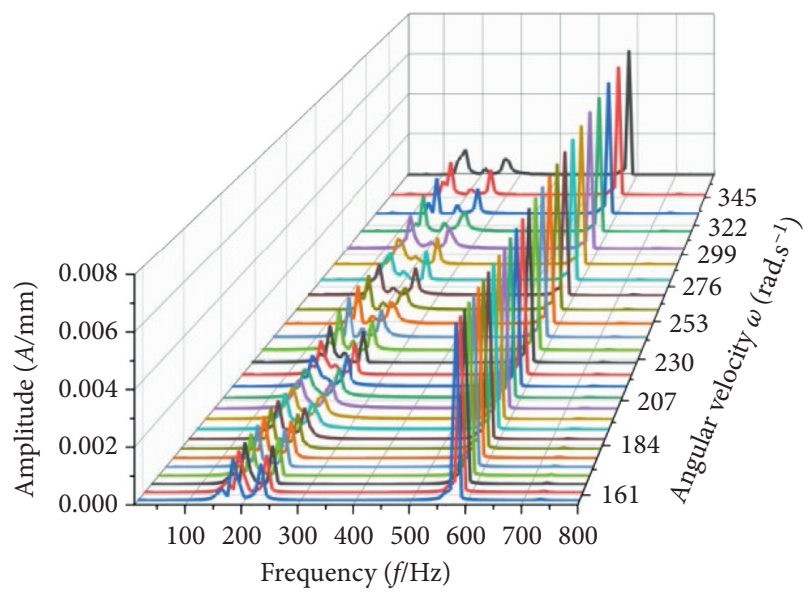

(a)

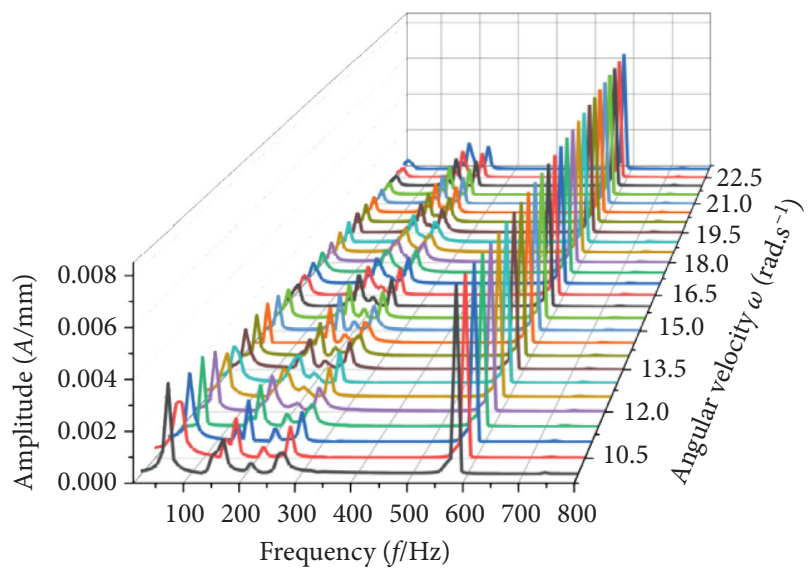

(c)

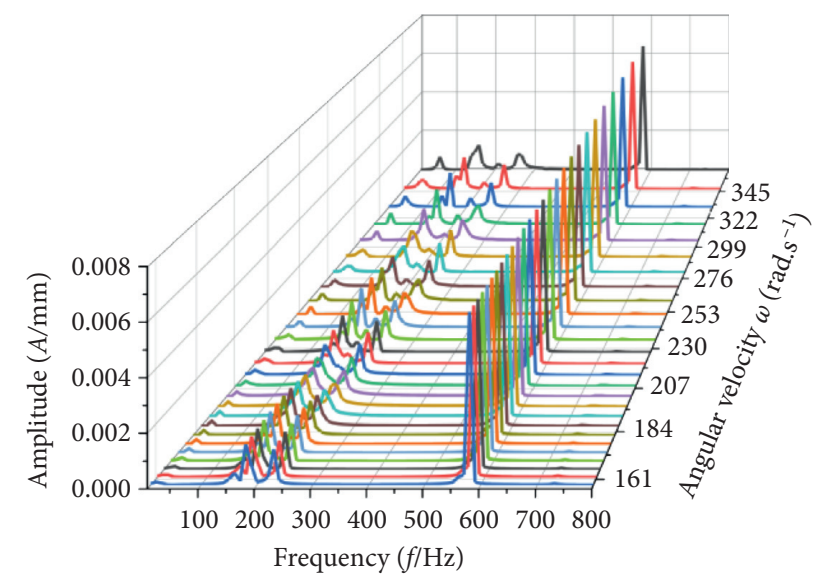

(b)

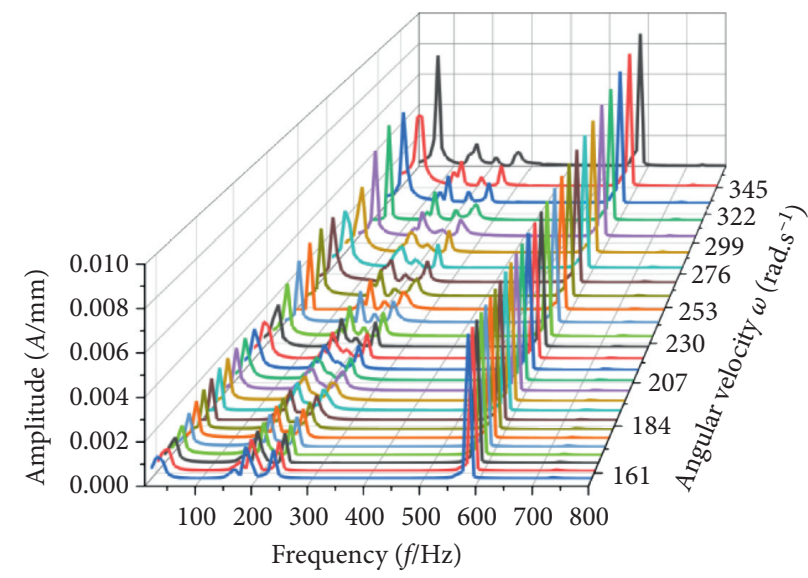

(d)

FIgURE 5: Spectrum diagram under different eccentricity. (a) $e=0.01 \mathrm{~mm}$. (b) $e=0.10 \mathrm{~mm}$. (c) $e=0.50 \mathrm{~mm}$. (d) $e=1.00 \mathrm{~mm}$.

The amplitude of both components is increased. The rotation frequency value increases with the increase of rotor speed, while the high frequency value is about $580 \mathrm{~Hz}$, which has nothing to do with rotor speed. The results of this study confirm the "frequency fixed" characteristics of polygonal wear found in theoretical analysis and field tests.

As can be seen from Figure 6, when the rotation frequency is $30 \mathrm{~Hz}$, with the decrease of eccentricity, the amplitude corresponding to the rotation frequency gradually decreases until it disappears. However, the constant frequency is $579.56 \mathrm{~Hz}$, and its amplitude is almost unchanged; that is, the constant frequency has nothing to do with the eccentricity.

\subsection{Determination of Evolution Conditions of Polygonal Wear.} The above finite element simulation analysis verifies that the longitudinal vibration of wheel is the basic condition for generating polygonal wear of wheel and determines the longitudinal creep force $F_{x}$. By substituting it into (2), the characteristics of wheel polygonal wear can be drawn, and then the conditions for the evolution of wheel polygonal wear can be determined.
In order to study the influence of rotor speed on polygonal wear of wheels, transient analysis was carried out at $250 \mathrm{~km} / \mathrm{h} \sim 350 \mathrm{~km} / \mathrm{h}$, respectively, and the circumferential wear of wheels was drawn by combining with the formula of wear depth $\Delta r$ in formula (2). The wear shapes near the order $N=18$ and 23 are shown in Figure 7.

According to Figure 7, when the speeds are $240 \mathrm{~km} / \mathrm{h}$ and $260 \mathrm{~km} / \mathrm{h}$, the wheel wear will be gradually uniform after a long run. However, when the speed is $262 \mathrm{~km} / \mathrm{h}$ and $335 \mathrm{~km} / \mathrm{h}$, the wheels have obvious polygonal wear of 18 th order and 23rd order, respectively. By analyzing the frequencies at different speeds, it is found that polygonal wear occurs when the "constant frequency" $580 \mathrm{~Hz}$ is an integer multiple of the rotation frequency, and uniform wear occurs when the wheel is not an integer multiple. It can be seen that when the longitudinal vibration frequency of the wheel is an integer multiple of the wheel rotation frequency, the polygonal wear of the wheel will evolve rapidly. Therefore, if the relationship is destroyed, the generation and development of polygon can be effectively suppressed, and if it can be run at constant speed within the life cycle of wheel diameter, it will be considered as one of the methods.

So far, we have found that the condition for the evolution of polygon wear of wheel is that the longitudinal vibration of 


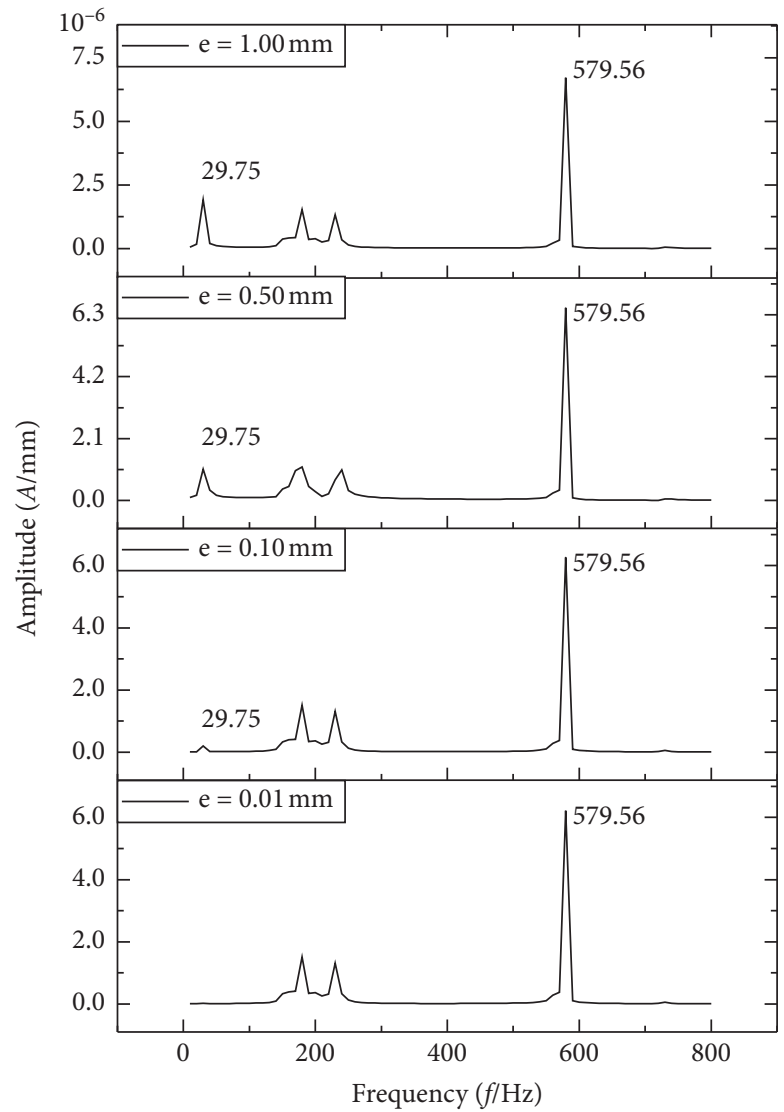

Figure 6: Spectrum diagram under different eccentricity with $f_{2}=30 \mathrm{~Hz}$.

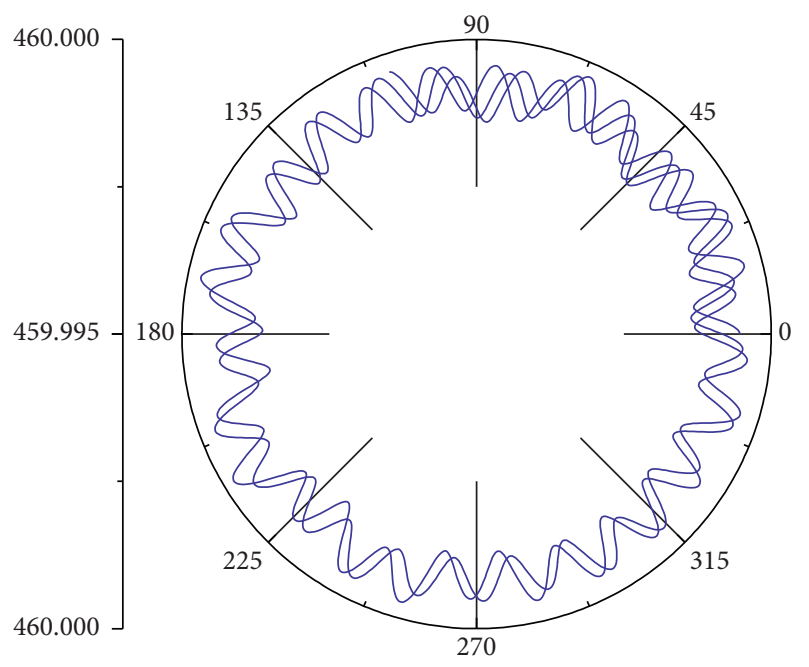

(a)

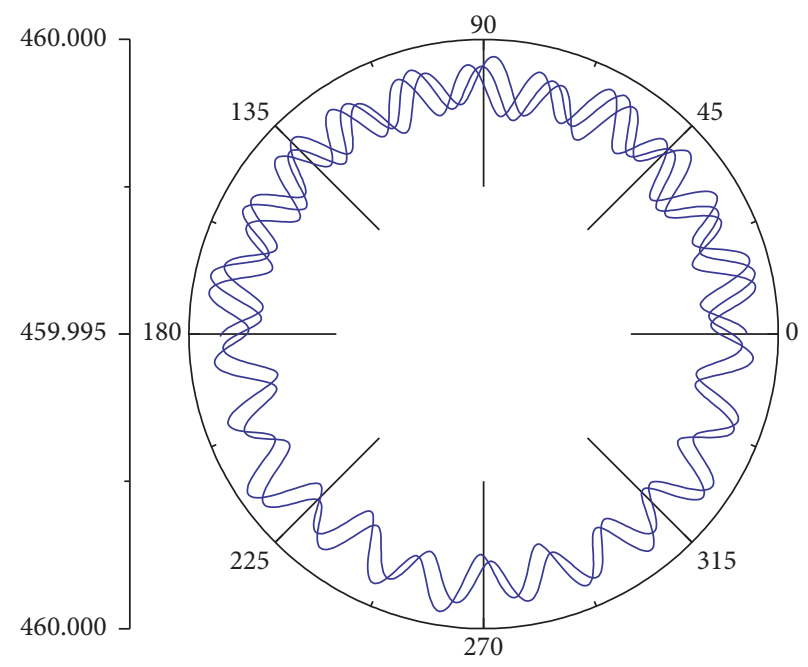

(b)

Figure 7: Continued. 


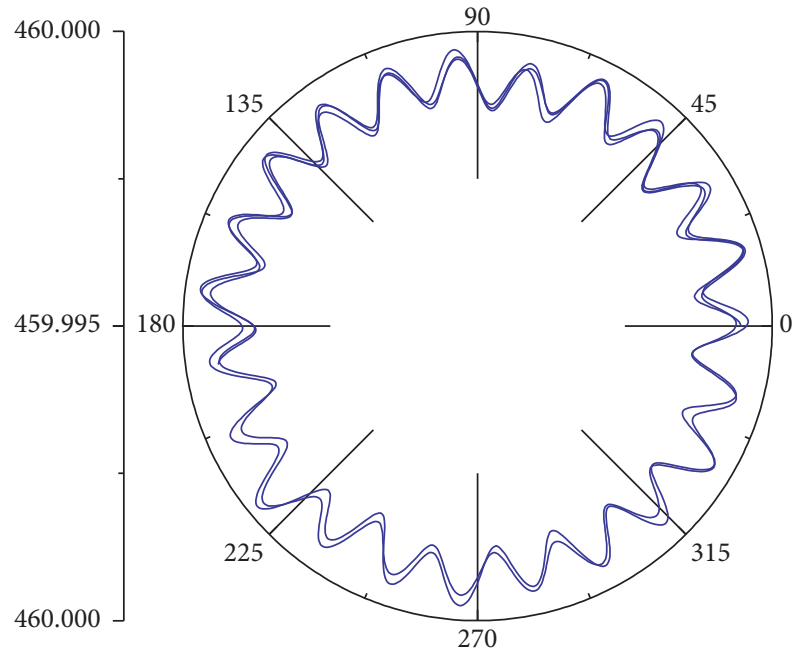

(c)

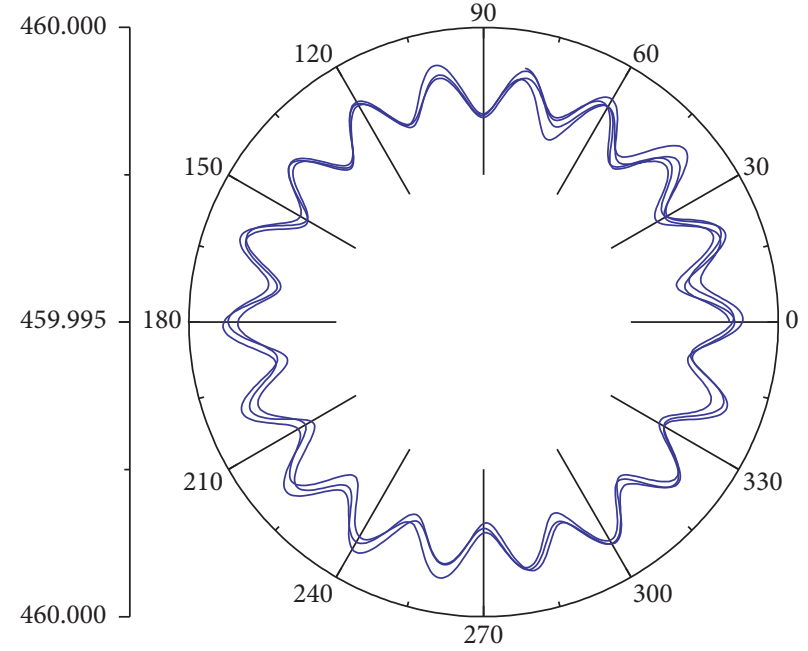

(d)

Figure 7: Wheel wear shape at different speeds. (a) $v=240 \mathrm{~km} / \mathrm{h}, N=25.22$. (b) $v=260 \mathrm{~km} / \mathrm{h}, N=23.2$. (c) $v=262 \mathrm{~km} / \mathrm{h}, N=23$. (d) $v=335 \mathrm{~km} / \mathrm{h}, N=18$.

\section{Frequency $=581.6 \mathrm{~Hz}$

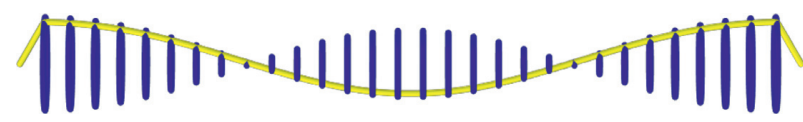

FIGURE 8: Vibration mode of third-order wheelset bending.

TABLE 3: Natural frequency of rotor system of wheelset $(\mathrm{Hz})$.

\begin{tabular}{lccc}
\hline & $\begin{array}{c}\text { Rotation effect is not considered } \\
\text { Flexible wheel rigid track }\end{array}$ & Flexible wheel flexible track & $\begin{array}{c}\text { Rotation effect is considered } \\
\text { Flexible wheel flexible track }\end{array}$ \\
\hline 519.4 & 567.16 & 565.42 & 565.42 \\
559.49 & 567.19 & 580.73 & 580.56 \\
574.77 & 577.74 & 583.07 & 582.93 \\
593.11 & 578.03 & 584.48 & 584.33 \\
605.9 & 585.43 & 585.47 & 585.7 \\
608.93 & 585.45 & 586.78 & 587 \\
622.27 & 748.22 & 591.33 & 591.36 \\
648.97 & 769.92 & 621.8 & 621.81 \\
\hline
\end{tabular}

wheelset and the wheel rotation frequency follow the law of "constant frequency and divisible."

\section{Determination of Constant Frequency Source}

Through the statistical analysis of the measured data and the verification of the theoretical simulation, it is found that the wheel polygonal wear follows the rule of "constant frequency and integer multiple," but the source of this constant frequency remains to be further studied. Therefore, we use beam element and solid element to conduct modal analysis, respectively, and try to find the source of constant frequency around $580 \mathrm{~Hz}$.

The beam element finite element model established in (5) is used for modal analysis, and the first 10 order modal natural frequencies are obtained. The vibration mode of the wheelset system at about $580 \mathrm{~Hz}$ is shown in Figure 8 which shows that the natural frequency of this order is $581.6 \mathrm{~Hz}$, and the corresponding vibration mode is third-order wheelset bending.

In order to study the relationship between constant frequency and track, wheelset, and their coupling effect, we take $60 \mathrm{~kg}$ track section, the length of $6.0 \mathrm{~m}$, sleeper spacing of $625 \mathrm{~mm}$, fastener width of $170 \mathrm{~mm}$, fastener vertical stiffness of $20 \mathrm{MN} / \mathrm{m}$, bogie fixed wheelbase of $2.5 \mathrm{~m}$, and wheel track wear coefficient $\mu=0.25$. The solid finite element model of wheel track coupling is established for modal analysis. The influence of rotation effect on the natural frequency of wheel track coupling system is studied under three conditions: flexible wheelset and rigid track, rigid wheelset and flexible track, and flexible wheelset and flexible track. The specific analysis results are shown in Table 3 and Figure 9.

As Table 3 shows, it can be seen from contrasting the natural frequencies of rigid wheelset and flexible track and flexible wheelset and rigid track which do not consider the 


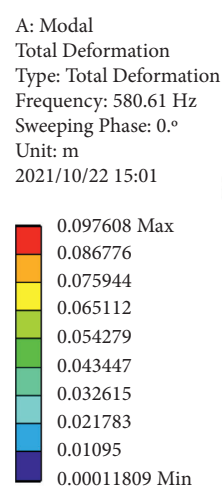

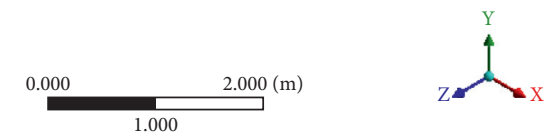

(a)

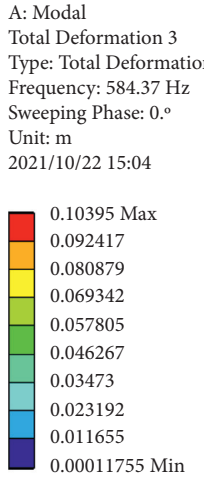

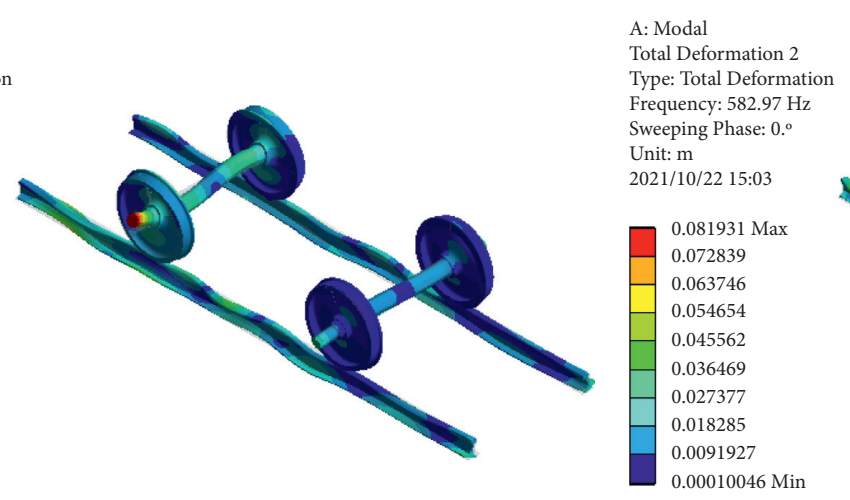
Deformation $82.97 \mathrm{~Hz}$ 021/10/22 15:03
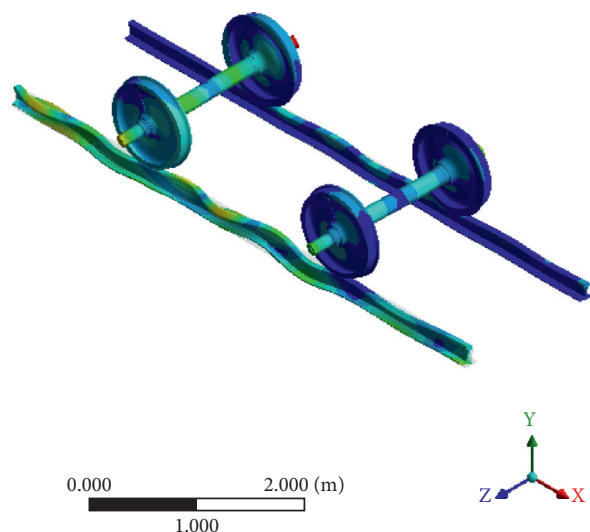

(b)
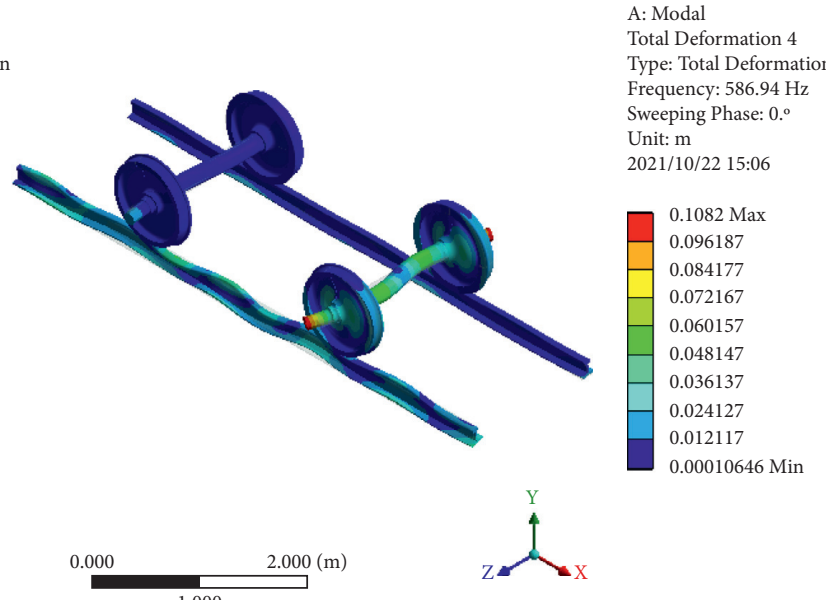

(c)

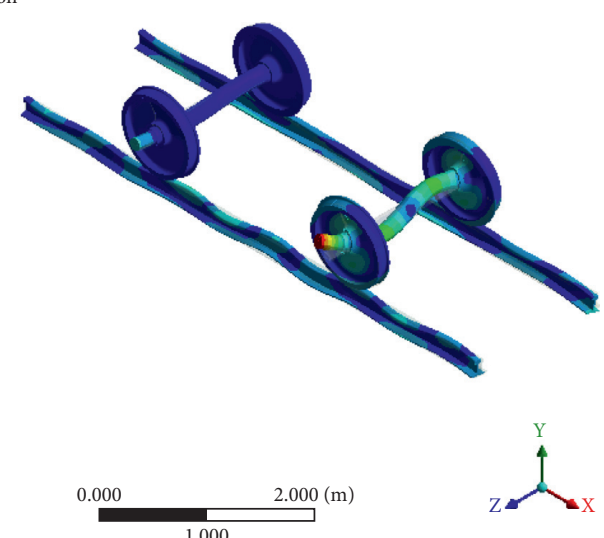

(d)

FIGURE 9: Vibration mode of wheel track coupling system with $\omega=180 \mathrm{rad} / \mathrm{s}$. (a) Wheelset $3 \mathrm{rd}$ vertical bending and track 8 th lateral bending. (b) Wheelset 3rd vertical bending and track 8th lateral bending. (c) Wheelset 3rd vertical bending and track 8th lateral bending and vertical bending. (d) Wheelset 3rd vertical bending and track 8 th vertical bending.

rotation effect that flexible wheelset and rigid track show more natural frequency close to the constant frequency of $580 \mathrm{~Hz}$. It can be shown that the track flexibility has little effect on the natural frequency near the constant frequency, while the wheelset's contribution to the constant frequency is greater than that of the track. This can also be seen in the analysis of flexible wheelset and flexible track. Although the contribution of track flexibility to "constant frequency" is little, it is more realistic to consider both wheelset and track as flexible. Therefore, when we study the influence of different rotor speeds on the natural frequency of the wheel track coupling system, we consider wheel track as flexible. Considering the rotation effect, the natural frequencies of the wheel track coupling system at different rotor speeds all show five values close to "constant frequency." It shows that the rotor speed has little influence on the natural frequency, which is consistent with the previous simulation analysis.

The vibration modes of flexible wheelset and track at speed of $180 \mathrm{rad} / \mathrm{s}$ are shown in Figure 9. The flexible wheel track vibration near the "constant frequency" corresponds to the third-order vertical bending of the wheelset, while the track presents 8th-order lateral bending, 8th-order lateral bending torsion coupling, and 8th-order vertical bending, respectively.

To sum up, the reason for the "constant frequency" phenomenon of about $580 \mathrm{~Hz}$ is mainly the third-order vertical bending of wheelset and the 8th-order coupling bending of track. The track flexibility and speed have a little effect on the "constant frequency" of wheel track coupling system.

\section{Conclusion}

The theoretical analysis and measured verification of the generation and evolution conditions of wheel polygonal wear are carried out based on the wear work model, and the wheelset rotor dynamics model considering wheel eccentricity is established for numerical simulation verification. The following conclusions are obtained: 
(1) The generation and evolution of wheel polygon wear present the characteristics of "constant frequency and integer multiple." The longitudinal vibration of wheelset is the basic condition for the generation of wheel polygonal wear, and its vibration frequency is constant. When the frequency is the integral multiple of wheel rotation frequency, the wheel polygonal wear evolves rapidly.

(2) The "constant frequency" of wheel polygonal wear is consistent with the natural frequency of the thirdorder vertical bending of wheelset excited by wheel rotation and the eighth-order coupled bending vibration of track.

(3) Constant rotor speed operation in the life cycle of wheel diameter can relieve the wheel polygon fault.

\section{Data Availability}

The underlying data supporting the results of your study can be found in References.

\section{Conflicts of Interest}

The authors declare that they have no conflicts of interest.

\section{Acknowledgments}

The authors acknowledge the financial support from the National Natural Science Foundation of China (no. 11872045), Youth Science Foundation of Gansu Province (no. 20JR10RA262), and Tianyou Innovation Team of Lanzhou Jiaotong University (no. TY202006).

\section{References}

[1] D. W. Barke and W. K. Chiu, "A review of the effects of outof-round wheels on track and vehicle components," Proceedings of the Institution of Mechanical Engineers - Part F: Journal of Rail and Rapid Transit, vol. 219, no. 3, pp. 151-175, 2005.

[2] M. Meywerk, "Polygonalization of railway wheels," Archive of Applied Mechanics, vol. 69, no. 2, pp. 105-120, 1999.

[3] A. Johansson and C. Andersson, "Out-of-round railway wheels-a study of wheel polygonalization through simulation of three-dimensional wheel-rail interaction and wear," Vehicle System Dynamics, vol. 43, no. 8, pp. 539-559, 2005.

[4] X. Wu, S. Rakheja, W. Cai, M. Chi, A. K. W. Ahmed, and S. Qu, "A study of formation of high order wheel polygonalization," Wear, vol. 424-425, pp. 1-14, 2019.

[5] Y. Ye, D. Shi, P. Krause, Q. Tian, and M. Hecht, "Wheel flat can cause or exacerbate wheel polygonization," Vehicle System Dynamics, vol. 58, no. 10, pp. 1575-1604, 2019.

[6] P. T. Torstensson, J. C. O. Nielsen, and L. Baeza, "Dynamic train-track interaction at high vehicle speeds-Modelling of wheelset dynamics and wheel rotation," Journal of Sound and Vibration, vol. 330, no. 22, pp. 5309-5321, 2011.

[7] E. Brommundt, "A simple mechanism for the polygonalization of railway wheels by wear," Mechanics Research Communications, vol. 24, no. 4, pp. 435-442, 2012.
[8] P. Meinke and S. Meinke, "Polygonalization of wheel treads caused by static and dynamic imbalances," Journal of Sound and Vibration, vol. 227, no. 5, pp. 979-986, 1999.

[9] X. S. Jin, Y. Wu, S. L. Liang, Z. F. Wen, X. W. Wu, and P. Wang, "Analysis of polygonal wear, mechanism, influence and countermeasures of high-speed train wheels," Journal of Mechanical Engineering, vol. 56, no. 16, pp. 118-136, 2020.

[10] B. Peng, S. Iwnicki, P. Shackleton, and D. Crosbee, "Comparison of wear models for simulation of railway wheel polygonization," Wear, vol. 436-437, no. 203010, pp. 1-13, 2019.

[11] W. Liu, W. Ma, S. Luo, and Y. Tian, "The mechanism of wheelset longitudinal vibration and its influence on periodical wheel wear," Proceedings of the Institution of Mechanical Engineers - Part F: Journal of Rail and Rapid Transit, vol. 232, no. 2, pp. 396-407, 2018.

[12] Q. H. Guan, X. Zhao, Z. F. Wen, and X. S. Jin, "Calculation method of normal contact stiffness based on Hertz contact theory," Journal of Southwest Jiaotong University, vol. 56, no. 4, pp. 883-890, 2021.

[13] X. N. Zhao, G. X. Chen, J. Z. Lv, S. Zhang, B. W. Wu, and Q. Zhu, "Study on the mechanism for the wheel polygonal wear of high-speed trains in terms of the frictional self-excited vibration theory," Wear, vol. 426-427, pp. 1820-1827, 2019.

[14] X. N. Zhao, G. X. Chen, Z. Y. Huang, and C. G. Xia, "Study on the different effects of power and trailer wheelsets on wheel polygonal wear," Shock and Vibration, vol. 2020, Article ID 2587152, 12 pages, 2020.

[15] W. B. Cai, M. R. Chi, X. W. Wu et al., "Experimental and numerical analysis of the polygonal wear of high-speed trains," Wear, vol. 440-441, no. 2203079, pp. 1-12, 2019. 